\title{
Prognostic performance of clinical assessment tools following hip fracture in patients with chronic kidney disease
}

\author{
Henry H. L. Wu ${ }^{1,2}$ (D) Reinier Van Mierlo ${ }^{3} \cdot$ George McLauchlan ${ }^{4} \cdot$ Kirsty Challen $^{5} \cdot$ Sandip Mitra ${ }^{2,6,7,8}$. \\ Ajay P. Dhaygude ${ }^{1,2} \cdot$ Andrew C. Nixon ${ }^{1,2,7}$ iD
}

Received: 29 September 2020 / Accepted: 8 February 2021 / Published online: 8 March 2021

(c) The Author(s) 2021

\begin{abstract}
Purpose People living with chronic kidney disease (CKD) are at a higher risk of hip fracture with an associated increased mortality risk compared to individuals without CKD. Our study aimed to evaluate the clinical assessment tools that best predict mortality risk following hip fracture for patients with CKD.

Methods Patients with CKD G3b-5D admitted to Lancashire Teaching Hospitals NHS Foundation Trust, U.K. between June 2013 and Dec 2019 were included. The association between CKD and post-fracture mortality risk was evaluated. All patients were assessed using tools that evaluated frailty status, co-morbidity, pre-operative risk, functional status and cardiopulmonary fitness. Receiver operating characteristic curve analyses were performed to determine the prognostic accuracy of the assessment tools for 30 day and 1 year mortality following hip fracture in patients with CKD.

Results 397 patients fulfilled inclusion criteria with a mean age of $83.5 \pm 9.2$ years. Older age, female sex, intracapsular fracture and more severe CKD, co-morbidity and frailty status were all associated with an increased mortality risk. Patients with dialysis-dependent CKD and severe/very severe frailty had a hazard ratio for mortality of $2.55(95 \% \mathrm{Cl} 2.11-2.98)$ and 3.11 (95\% Cl 2.47-3.93), respectively. The Clinical Frailty Scale demonstrated the best prognostic accuracy for both 30 day [Area Under the Curve (AUC) 0.91, 95\% Cl 0.84-0.97] and 1 year mortality (AUC 0.93, 95\% Cl 0.87-1.00).

Conclusion Patients with advanced CKD and severe frailty have a high mortality risk following hip fracture. The Clinical Frailty Scale is an excellent prognostic tool for mortality in this setting and could be easily incorporated into routine clinical practice.
\end{abstract}

Keywords Chronic kidney disease $\cdot$ Hip fracture $\cdot$ Geriatric nephrology $\cdot$ Frailty $\cdot$ Mortality $\cdot$ Prognosis

Henry H. L. Wu

Henry.wu@lthtr.nhs.uk

1 Department of Renal Medicine, Lancashire Teaching Hospitals NHS Foundation Trust, Royal Preston Hospital, Sharoe Green Lane, Preston PR2 9HT, UK

2 Faculty of Medical and Human Sciences, University of Manchester, Manchester, UK

3 Department of Physiotherapy, Lancashire Teaching Hospitals NHS Foundation Trust, Royal Preston Hospital, Preston, UK

4 Department of Orthopedics \& Traumatology, Lancashire Teaching Hospitals NHS Foundation Trust, Royal Preston Hospital, Preston, UK
5 Department of Accident and Emergency, Lancashire Teaching Hospitals NHS Foundation Trust, Royal Preston Hospital, Preston, UK

6 Manchester Academy of Health Sciences (MAHSC), Manchester University NHS Foundation Trust, Manchester, UK

7 Department of Renal Medicine, Manchester University NHS Foundation Trust, Manchester, UK

8 National Institute of Health Research D4D MedTech and In Vitro diagnostics Co-operatives (MICs), Sheffield, UK 


\section{Introduction}

Hip fracture presentations are a global public health burden [1]. There were an estimated 1.6 million hip fractures in 2000; this is projected to increase to 6.3 million by 2050 with a growing elderly population [2]. People living with chronic kidney disease (CKD) have a greater risk of falls leading to hip fracture [3]. Individuals with end-stage kidney disease (ESKD) are reported to have a risk of falls and hip fracture between 4 and 14 times greater than those without CKD $[4,5]$. There are higher risks of poor health outcomes for patients living with CKD after sustaining hip fracture. Increased morbidity and mortality following hip fracture is compounded by factors such as frailty [6], sarcopenia [7] and CKD-associated mineral and bone disorder (CKD-MBD) [8]. A significant decline in functional status following acute trauma is frequently observed for patients with various comorbidities including CKD [9]. Due to this marked decline, rehabilitation following hip fracture is more difficult for patients with CKD compared to the general population [9]. Importantly, mortality outcomes are worse for patients with reduced functional status [10].

Though multiple risk factors are suggested, the most important predictors of mortality risk following hip fracture are unclear for patients living with CKD. Tools prognosticating mortality risk following hip fracture have been previously suggested and are widely applied in practice for the general population [11-13]. However, these tools have not been validated for patients who have CKD. Risk stratification tools that guide clinical decision-making may optimize outcomes in CKD populations after acute trauma. Our study aims to evaluate risk factors for mortality and the relative prognostic accuracy of various clinical assessment tools following hip fracture for patients living with CKD.

\section{Methods}

\section{Study design and participant selection}

Patients with non-dialysis and dialysis-dependent CKD (G3b-5D) admitted to Lancashire Teaching Hospitals NHS Foundation Trust with a hip fracture were included in this study. Our study was a secondary analysis of a larger prospective cohort study, which investigated mortality outcomes in the general population admitted with hip fracture.

Data were collected between June 2013 and December 2019. Formal patient consent was not required, because data were collected as part of routine clinical practice. Ethical approval was obtained from the North West Health Research Council, UK and the NHS Health Research Authority.

\section{Data collection}

Demographic and clinical characteristic data including age, sex, CKD stage, living arrangements and type of hip fracture sustained were recorded within $48 \mathrm{~h}$ of hospital admission. Mortality from the date of hospital admission was recorded. Clinical assessment tools evaluated in our study were categorized into frailty, co-morbidity, pre-operative risk, functional status and cardiopulmonary fitness assessment tools.

\section{Frailty}

The Clinical Frailty Scale (CFS) [14] is an ordinal frailty assessment tool that provides nine descriptions of levels of fitness or frailty. It relies upon a health professional's assessment of an individual's frailty status. Individuals with a CFS score of 1-2 are considered fit or well [15]. A CFS score of 3-4 suggests individuals may have a health problem but managing well, though not regularly active, or they may be becoming vulnerable, but are not overtly frail [15]. A CFS score of 5-6 identifies those with signs of frailty but otherwise have some degree of independence [15]. Individuals with a CFS score of 7-9 have severe or very severe frailty [15].

The CKD Frailty Index Lab (CKD FI-LAB) [16] is a composite score based upon the FI-LAB in which blood pressure readings and laboratory variables are used to estimate frailty status. The FI-LAB has been studied in the general older population and is predictive of clinical outcomes $[17,18]$. The CKD FI-LAB is calculated by the total number of deficits divided by the total number of variables measured. "Appendix" lists the variables included in the CKD FILAB scoring. A higher CKD FI-LAB score suggests greater degree of frailty.

\section{Co-morbidity}

Charlson's Co-morbidity Index (CCI) [19] is a composite score of co-morbidity status that is predictive of mortality in the general and CKD population [20]. A higher CCI score represents greater co-morbidity.

\section{Pre-operative risk scores}

The American Society of Anesthesiologists (ASA) Index [21] is a five-category ordinal classification system used to determine pre-operative fitness for surgery. It ranges from category 1 , a healthy person, to category 5 , a moribound person who is not expected to survive beyond $24 \mathrm{~h}$ with or without surgery. The Nottingham Hip Fracture Score (NHFS) [22] is a 10-point scoring system, which aims to predict 30 day mortality risk following hip fracture. A higher 
NHFS score represents higher mortality risk. The Sernbo score [23] is used to predict mortality risk following hip fracture and is scored out of 20. Scoring is determined from 4 components: age, social situation, mobility and mental status. A lower Sernbo score represents higher mortality risk.

\section{Functional status}

The Karnofsky Performance Status (KPS) score [24] measures functional status through assessing an individual's ability to perform everyday activities. The KPS score ranges from 0 to 100, with higher KPS scores suggesting better functional status.

\section{Cardiopulmonary fitness}

The Duke Activity Status Index (DASI) [25] is a 12-item self-administered questionnaire that measures functional capacity. Through the formula $(0.43 \times$ DASI $)+9.6$ $\times$ DASI $+9.6 \times$ DASI +9.6 , an estimated $\mathrm{VO}_{2}$ peak value can be calculated [26]. The estimated $\mathrm{VO}_{2}$ peak provides an estimation of an individual's peak oxygen uptake and has been proven to be a reliable measure of cardiorespiratory fitness [27].

\section{Statistical analysis}

All statistical analyses were performed on Stata 14.2 (StataCorp, College Station, TX, USA) or StatsDirect Statistical Software (version 3.2.10, 03/05/2020). Descriptive statistics summarized demographic and clinical data. Frequencies and percentages were used to present categorical data. Mean \pm SD values were presented for continuous variables that were normally distributed. Otherwise, continuous data were presented as median $\pm \mathrm{IQR}$.

Multivariate Cox regression analysis was used to evaluate the association between CKD and post-fracture mortality risk. Independent variables were selected a priori. Age (for each 1 year increase), sex, intracapsular hip fracture, CKD stage (with CKD G3b being the reference), CCI (for each unit of increase) and CFS score (with CFS 1-2 being the reference category). The assumption of proportional hazards was assessed by reviewing the significance of time-variable interactions.

An area under the curve (AUC) value was calculated through receiver operating characteristic (ROC) curve analyses to assess each assessment tool's prognostic value for 30 day and 1 year mortality. A two-tailed $p$ value $<0.05$ was considered statistically significant. As a secondary analysis, there was no a priori sample size calculation.

\section{Results}

Amongst 2743 patients hospitalized following hip fracture between June 2013 and December 2019, there were 397 patients living with CKD G3b-5D. Table 1 demonstrates the demographic and clinical characteristics of patients with CKD G3b-5D in this study. The mean age was $83.5 \pm 9.2$ years and $63 \%$ were female. Two hundred and fifty-three patients (64\%) had CKD G3b. There were 42 patients $(11 \%)$ receiving long-term dialysis (CKD G5D). Two hundred and twenty-five patients (57\%) were admitted from home with the remaining patients admitted either from nursing or residential home. One hundred and eighty-three patients (46\%) had a CFS 7-9 score. Figure 1 describes the distribution of CFS scores observed. Two hundred and one patients (51\%) sustained a displaced, intracapsular fracture. One hundred and sixty-one patients $(41 \%)$ received a hemiarthroplasty and 127 patients (32\%) were treated with a dynamic hip screw procedure. Other observed treatment modalities for hip fracture included total hip replacement, intramedullary nail insertion, cannulated hip screw insertion and conservative management.

\section{Risk factors for mortality following hip fracture for patients living with CKD}

Figure 2 illustrates a hazard ratio (HR) forest plot of risk factors for mortality following hip fracture in patients with CKD. The median follow-up was 27.2 months. The HR for each year increase in age was $1.30(95 \% \mathrm{Cl} 1.04-1.59)$. Female patients (HR 1.46, 95\% Cl 1.09-1.93) and those who sustained an intracapsular fracture (HR $1.71,95 \% \mathrm{Cl}$ 1.32-2.13) had a greater mortality risk. The HR for each unit of increase in CCI score was $2.63(95 \% \mathrm{Cl} 2.01-3.27)$. Patients with CKD G5D (HR 2.55, 95\% Cl 2.11-2.98) had higher HR compared to those with CKD G4 (HR 1.44, 95\% $\mathrm{Cl} 1.13-1.77)$ and G5 (HR 1.82, 95\% Cl 1.40-2.28). Patients scoring CFS 7-9 (HR 3.11, 95\% Cl 2.47-3.93) had higher HR compared to those scoring CFS 5-6 (HR $1.78,95 \% \mathrm{Cl} 1.42-2.16)$ and CFS 3-4 (HR 1.13, 95\% Cl $0.91-1.34)$.

\section{Prognostic accuracy of clinical assessment tools for mortality following hip fracture in patients living with CKD}

Table 2 summarizes the prognostic accuracy of selected clinical assessment tools for 30 day and 1 year mortality. All 397 patients were evaluated for 30 day mortality, whilst 1 year follow-up data were only available for 299 
Table 1 Demographic and clinical characteristics amongst patients living with CKD admitted with hip fracture

\begin{tabular}{|c|c|}
\hline Demographic and clinical characteristics & $\begin{array}{l}\text { Patients with } \\
\text { CKD 3b-5D } \\
(n=397)\end{array}$ \\
\hline Age in years, mean $\pm S D$ & $83.5 \pm 9.2$ \\
\hline Female $(\%)$ & 63 \\
\hline \multicolumn{2}{|l|}{ CKD Stage, $n(\%)$} \\
\hline $\mathrm{G} 3 \mathrm{~b}$ & $253(64)$ \\
\hline G4 & $65(16)$ \\
\hline G5 & $37(9)$ \\
\hline G5D & $42(11)$ \\
\hline Body mass index, mean \pm SD & $23 \pm 6.1$ \\
\hline \multicolumn{2}{|l|}{ Blood pressure in $\mathrm{mmHg}$, mean $\pm \mathrm{SD}$} \\
\hline Systolic & $141 \pm 17.3$ \\
\hline Diastolic & $82 \pm 11.1$ \\
\hline Hemoglobin in $\mathrm{g} / \mathrm{dL}$, mean $\pm \mathrm{SD}$ & $11.4 \pm 1.2$ \\
\hline Serum creatinine in $\mu \mathrm{mol} / \mathrm{L}$, mean $\pm \mathrm{SD}$ & $172.0 \pm 140.3$ \\
\hline Serum albumin in $\mathrm{g} / \mathrm{dL}$, mean $\pm \mathrm{SD}$ & $3.7 \pm 0.6$ \\
\hline \multicolumn{2}{|l|}{ Living arrangements, $n(\%)$} \\
\hline Home & $225(57)$ \\
\hline Residential home & $23(5)$ \\
\hline Nursing home & $149(38)$ \\
\hline \multicolumn{2}{|l|}{ Frailty assessment } \\
\hline CFS $1-2, n(\%)$ & $0(0)$ \\
\hline CFS $3-4, n(\%)$ & $40(10)$ \\
\hline CFS 5-6, $n(\%)$ & $174(44)$ \\
\hline CFS 7-9, $n(\%)$ & $183(46)$ \\
\hline CKD FI-LAB, mean \pm SD & $0.352 \pm 0.115$ \\
\hline \multicolumn{2}{|l|}{ Co-morbidity } \\
\hline $\mathrm{CCI}$, mean $\pm \mathrm{SD}$ & $12.7 \pm 3.3$ \\
\hline \multicolumn{2}{|l|}{ Pre-operative risk scores } \\
\hline ASA Index, median (IQR) & $3(1)$ \\
\hline $\mathrm{NHFS}$, mean $\pm \mathrm{SD}$ & $5.8 \pm 1.6$ \\
\hline Sernbo score, mean \pm SD & $12.8 \pm 3.6$ \\
\hline \multicolumn{2}{|l|}{ Functional status } \\
\hline KPS, median (IQR) & $50(30)$ \\
\hline \multicolumn{2}{|l|}{ Cardiopulmonary fitness } \\
\hline Estimated $\mathrm{VO}_{2}$ peak in $\mathrm{L} / \mathrm{min}$, mean $\pm \mathrm{SD}$ & $13.9 \pm 4.1$ \\
\hline \multicolumn{2}{|l|}{ Type of hip fracture, $n(\%)$} \\
\hline Intracapsular undisplaced & $22(5)$ \\
\hline Intracapsular displaced & $201(51)$ \\
\hline Intertrochanteric & $151(38)$ \\
\hline Subtrochanteric & $11(3)$ \\
\hline Pathological & $12(3)$ \\
\hline
\end{tabular}

$C K D$ Chronic Kidney Disease, CFS Clinical Frailty Scale, CKD FI-LAB Chronic Kidney Disease Frailty Index Lab, CCI Charlson's Comorbidity Index, ASA Index American Society of Anesthesiologists Index, NHFS Nottingham Hip Fracture Score, CFS Clinical Frailty Scale, KPS Karnofsky Performance Status Score patients. Thirty-day and 1 year mortality rates were $9.6 \%$ and $38.0 \%$, respectively.

The CFS had the best overall prognostic performance amongst the tools assessed. The CKD FI-LAB, CCI and KPS demonstrated good predictive accuracy for 30 day and 1 year mortality. AUC values for the pre-operative assessment scores, ASA index and NHFS were statistically significant for 30 day, but not for 1 year mortality. The AUC value for estimated $\mathrm{VO}_{2}$ peak was not statistically significant for 30 day or 1 year mortality outcomes.

\section{Discussion}

To our knowledge, this is the first study that investigates the prognostic performance of clinical assessment tools following hip fracture for patients living with CKD. Selection of clinical assessment tools is guided by identifying the major risk factors for mortality within this context.

Similar to previous studies, older age was demonstrated to be an important risk factor for mortality following hip fracture in CKD [28, 29]. Nitsch et al. concluded that there is almost a twofold increase in hip fracture-related mortality amongst older people with an eGFR $<45 \mathrm{ml} / \mathrm{min} / 1.73 \mathrm{~m}^{2}$ [28]. Postmenopausal-related changes in bone and mineral metabolism observed in older women leads to greater osteoporotic risks [30]. CKD may exacerbate osteoporotic risks to a greater extent for women compared to men due to its effects on bone and mineral metabolism [8].

There is limited data directly comparing mortality outcomes between dialysis-dependent and non-dialysis CKD groups following hip fracture. However, patients on dialysis have a higher risk of in-patient mortality following hip fracture [31-33]. Hickson et al. noted that $8 \%$ of dialysisdependent patients who experienced a hip fracture died before hospital discharge [31]. Furthermore, there was a threefold increase in adjusted mortality risk for the dialysisdependent group compared to patients with non-dialysisdependent CKD [31].

Our study demonstrates that sustaining an intracapsular hip fracture is associated with an increased mortality risk for patients with CKD. The impact of having an intracapsular hip fracture from acute trauma should not be underestimated. Hemiarthroplasty, total hip replacement or internal fixation is indicated in most circumstances to treat intracapsular fractures [34]. The type of operation performed depends on multiple factors, such as hip fracture displacement, age, co-morbidity, functional status and hip joint condition prior to fracture [35]. There are patients who do not undergo total hip replacement following a displaced intracapsular hip fracture because of the surgical risks involved and no functional benefits are expected. Current evidence suggests better post-operative outcomes 
Fig. 1 Distribution of CFS scores amongst patients living with CKD admitted with hip fracture. This figure was created from StatsDirect Statistical Software (version 3.2.10, 03/05/2020)

Fig. 2 Hazard ratio forest plot of risk factors for mortality after hip fracture in patients living with CKD. CKD Chronic Kidney Disease, CCI Charlson's Co-morbidity Index, $C F S$ Clinical Frailty Scale. CKD $\mathrm{G} 3 \mathrm{~b}$ is the reference category for adjusted HR calculated for CKD G4, CKD G5 and CKD G5D. CFS $1-2$ is the reference category for adjusted HR calculated for CFS 3-4, CFS 5-6 and CFS 7-9. This figure was created from StatsDirect Statistical Software (version 3.2.10, 03/05/2020)

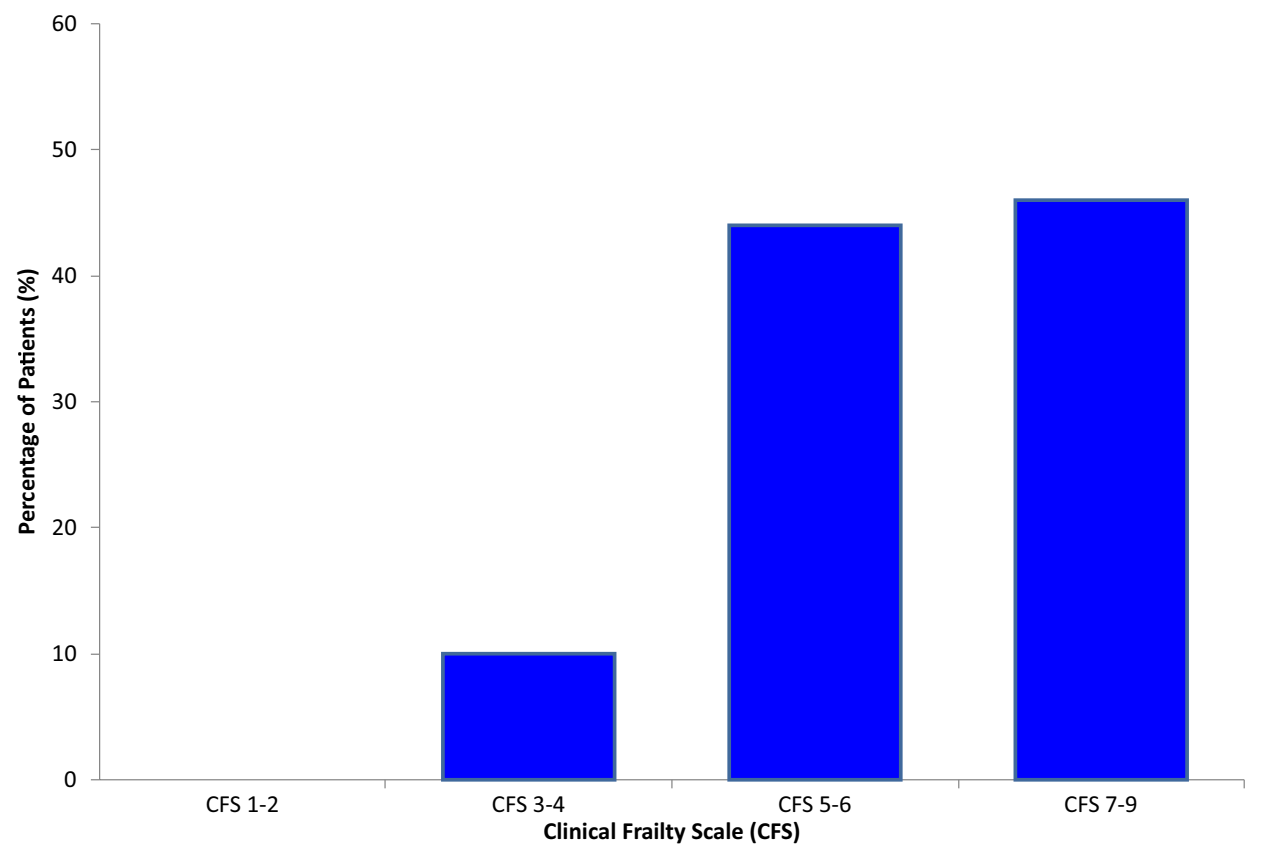

Age (years), for each 1 year increase in age

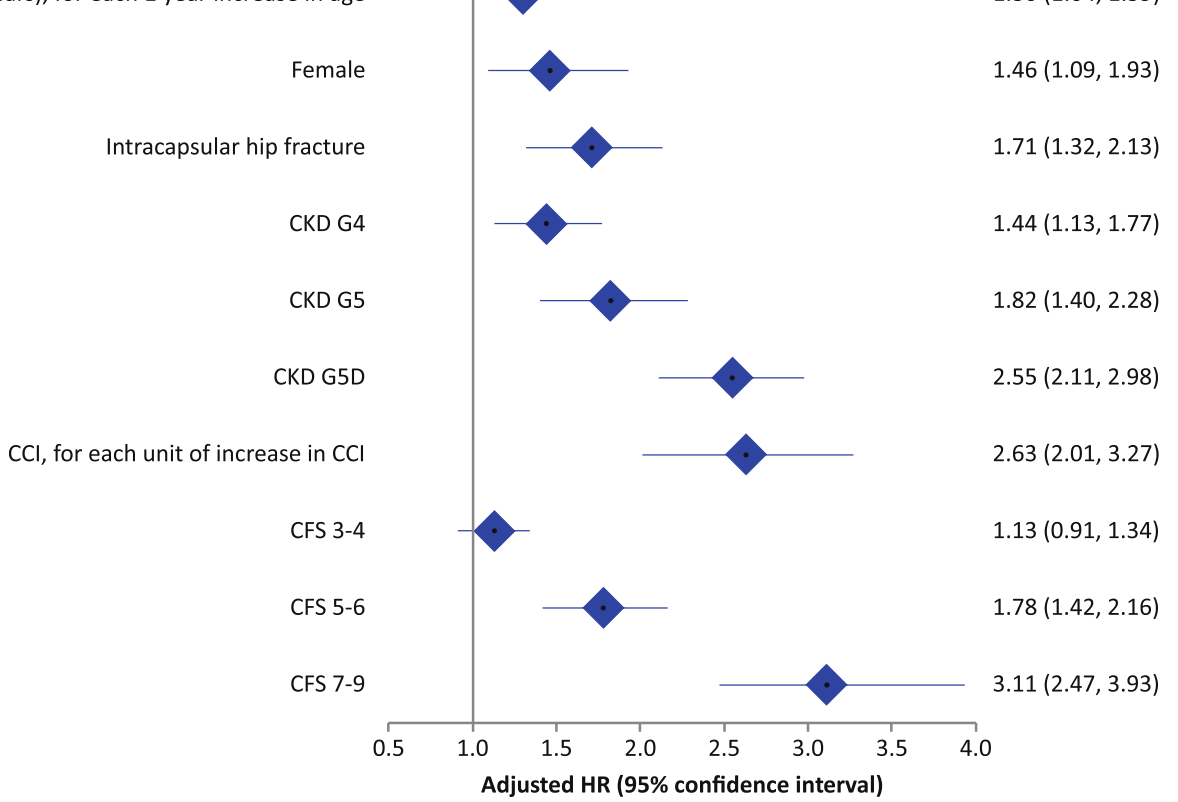

Moreover, a greater mortality risk was observed over the study follow-up period.

Frailty was associated with an increased mortality risk following hip fracture in patients with CKD in a graded fashion. The CFS displayed excellent prognostic accuracy and had the best performance amongst the clinical assessment tools evaluated in this study. The CFS is a practical tool, taking only a few minutes to complete, and is now widely used in the acute medical setting [40]. The CFS has been shown to have good diagnostic accuracy for physical frailty in patients living with CKD [16]. Since the onset of the cardiopulmonary complications and hyperparathyroidis post-operatively compared to the non-ESRD group [39]. 
Table 2 Prognostic accuracy of clinical assessment tools for 30 day and 1 year mortality after hip fracture in patients living with CKD

\begin{tabular}{|c|c|c|c|c|}
\hline & \multicolumn{2}{|c|}{30 day mortality $(n=397)$} & \multicolumn{2}{|c|}{1 year mortality $(n=299)$} \\
\hline & AUC value $(95 \% \mathrm{Cl})$ & $p$ value & AUC value $(95 \% \mathrm{Cl})$ & $p$ value \\
\hline \multicolumn{5}{|l|}{ Frailty assessment } \\
\hline CFS & $0.91(0.84-0.97)$ & $<0.001$ & $0.93(0.87-1.00)$ & $<0.001$ \\
\hline CKD FI-LAB & $0.78(0.71-0.85)$ & $<0.001$ & $0.83(0.77-0.90)$ & $<0.001$ \\
\hline \multicolumn{5}{|l|}{ Co-morbidity } \\
\hline $\mathrm{CCI}$ & $0.82(0.75-0.88)$ & $<0.001$ & $0.85(0.78-0.92)$ & $<0.001$ \\
\hline \multicolumn{5}{|l|}{ Pre-operative risk scores } \\
\hline ASA Index & $0.75(0.69-0.81)$ & $<0.001$ & $0.77(0.70-0.84)$ & 0.202 \\
\hline NHFS & $0.74(0.67-0.80)$ & $<0.001$ & $0.67(0.60-0.73)$ & 0.357 \\
\hline Sernbo score & $0.71(0.64-0.78)$ & $<0.001$ & $0.68(0.61-0.74)$ & $<0.001$ \\
\hline \multicolumn{5}{|l|}{ Functional status } \\
\hline KPS & $0.82(0.76-0.89)$ & $<0.001$ & $0.84(0.78-0.90)$ & $<0.001$ \\
\hline \multicolumn{5}{|l|}{ Cardiopulmonary fitness } \\
\hline Estimated $\mathrm{VO}_{2}$ peak & $0.69(0.62-0.76)$ & 0.246 & $0.73(0.67-0.80)$ & 0.512 \\
\hline
\end{tabular}

$C C I$ Charlson's Co-morbidity Index, CKD FI-LAB Chronic Kidney Disease Frailty Index Lab, CFS Clinical Frailty Scale, ASA Index American Society of Anesthesiologists Index, NHFS Nottingham Hip Fracture Score, KPS Karnofsky Performance Status Score
COVID-19 pandemic, the National Institute for Health and Care Excellence (NICE) published a COVID-19 critical care guideline that recommended the use of the CFS to inform care decisions in acute hospital admissions, including major trauma [41].

In our analysis, the CKD FI-LAB demonstrated good prognostic value for 30 day and 1 year mortality following hip fracture in patients living with CKD. A recent study suggested the CKD FI-LAB had poor diagnostic accuracy for frailty in patients living with advanced CKD [16]. Despite this finding, the FI-LAB has previously displayed excellent prognostic accuracy for mortality in the general elderly population $[17,18]$. In the context of hip fracture, the CKD FI-LAB had good prognostic accuracy in patients living with CKD. The usefulness of the CFS may be limited by the experience of the assessor; the CKD FI-LAB is a more objective assessment tool and, therefore, may potentially be a more reliable alternative.

The CCI is widely used in the assessment of co-morbidity status and has good prognostic accuracy for in-hospital mortality in the general older population following hip fracture [42, 43]. Patients with higher CCI scores in addition to CKD have an associated worse health-related quality of life (HRQOL) and an increased mortality risk after fracture [44]. Post-fracture rehabilitation outcomes are worse in patients with CKD compared to those without renal impairment [44]. A multivariate-adjusted risk prediction model evaluating the predictive ability of CCI for mortality from 1990 to 2007 in the US National Hospital Discharge Survey Study displayed AUC values of up to 0.77 [42]. Multiple sources advocate the use of CCI as a cost-effective assessment tool when treatment decisions are made for the general older population following acute trauma $[45,46]$. The applicability of CCI for this purpose in patients living with CKD requires further validation.

There is a significant association between functional status decline and increased mortality risk in patients living with advanced CKD $[47,48]$. Our results demonstrated that admission KPS assessment had good prognostic accuracy for 30 day and 1 year mortality. Literature evaluating the prognostic value of functional status for mortality outcomes following hip fracture in CKD cohorts is limited. Nevertheless, a preliminary study from Sakabe et al. highlighted prefracture ambulatory status as the only prognostic indicator of life expectancy following hip fracture in dialysis-dependent patients [49].

Data evaluating the prognostic accuracy of the ASA Index, NHFS, Sernbo Score and estimated $\mathrm{VO}_{2}$ peak following hip fracture in patients living with CKD has not been previously reported. The ASA Index, NHFS and Sernbo Score have been shown to be useful predictors of mortality outcomes following hip fracture in the general population [50-52]. However, in our study, these clinical assessment tools were demonstrated to have only poor or fair prognostic accuracy for post-fracture mortality in patients with CKD.

Notwithstanding our study's holistic approach and practical usefulness, there are recognized limitations. These results were collected from a single-centre with a predominantly White British population and may not be reproducible for a different patient population. Another limitation of our study is that test-retest reliability and inter-observer reliability was not assessed. A causative link between frailty, co-morbidity, functional status and mortality cannot be established due to the non-randomized controlled design of this study. Moreover, 
Table 3 The chronic kidney disease frailty index lab (CKD FI-LAB)

\begin{tabular}{|c|c|c|}
\hline Variable & Lower cut off & Upper cut off \\
\hline Systolic BP, mmHg & 90 & 140 \\
\hline Diastolic BP, mmHg & 60 & 90 \\
\hline Haemoglobin, g/L & 100 & $120^{\mathrm{a}}$ \\
\hline $\mathrm{MCV}, \mathrm{fl}$ & 82 & 98 \\
\hline White cell count, $\times 10^{9} / \mathrm{L}$ & 4.0 & 11.0 \\
\hline Platelet count, $\times 10^{9} / \mathrm{L}$ & 140 & 440 \\
\hline Ferritin, $\mu \mathrm{g} / \mathrm{L}$ & $100^{\mathrm{b}}$ & 800 \\
\hline Transferrin saturation, $\%$ & 20 & 50 \\
\hline Sodium, $\mathrm{mmol} / \mathrm{L}$ & 133 & 146 \\
\hline Potassium, mmol/L & 3.5 & 5.3 \\
\hline Bicarbonate, $\mathrm{mmol} / \mathrm{L}$ & 22 & 29 \\
\hline $\mathrm{CRP}, \mathrm{mg} / \mathrm{L}$ & 0 & 5 \\
\hline Corrected calcium, $\mathrm{mmol} / \mathrm{L}$ & 2.20 & 2.60 \\
\hline Phosphate, $\mathrm{mmol} / \mathrm{L}$ & 0.80 & 1.50 \\
\hline Alkaline phosphatase, U/L & 30 & 130 \\
\hline Albumin, $\mathrm{g} / \mathrm{L}$ & 35 & 50 \\
\hline Total protein, $\mathrm{g} / \mathrm{L}$ & 60 & 80 \\
\hline ALT, U/L & 0 & 41 \\
\hline Bilirubin, $\mu \mathrm{mol} / \mathrm{L}$ & 0 & 21 \\
\hline Prothrombin time, seconds & 9 & 12 \\
\hline Fibrinogen, g/L & 1.8 & 4.5 \\
\hline Folate, $\mu \mathrm{g} / \mathrm{L}$ & 3.9 & 19.8 \\
\hline TSH, mU/L & 0.35 & 5.00 \\
\hline $\mathrm{T} 4, \mathrm{pmol} / \mathrm{L}$ & 11.0 & 23.0 \\
\hline $\mathrm{B} 12, \mathrm{ng} / \mathrm{L}$ & 200 & $900 \mathrm{ng} / \mathrm{L}$ \\
\hline $\mathrm{HbA} 1 \mathrm{C}, \mathrm{mmol} / \mathrm{mol}$ & 20 & 41 \\
\hline Vitamin D, nmol/L & 50 & 150 \\
\hline
\end{tabular}

$B P$ Blood Pressure, $M C V$ Mean Corpuscular Volume, CRP C-Reactive Protein, ALT Alanine Transaminase, TSH Thyroid-Stimulating Hormone

${ }^{a}$ If the individual is on Erythropoietin Stimulating Agent. Otherwise, hemoglobin upper cut off $165 \mathrm{~g} / \mathrm{L}$ for women and $180 \mathrm{~g} / \mathrm{L}$ for men.

'If the individual's hemoglobin less than $110 \mathrm{~g} / \mathrm{L}$ and/or receiving Erythropoietin Stimulating Agent. Otherwise, ferritin lower cut off $20 \mu \mathrm{g} / \mathrm{L}$ for men and $15 \mu \mathrm{g} / \mathrm{L}$ for women

the influence of specific orthopedic interventions on post-fracture outcomes was not assessed. Research which compares outcomes of patients with CKD with hip fracture and other associated co-morbidities following different orthopedic interventions is needed.

In conclusion, patients with CKD, particularly advanced CKD, and patients with CKD and severe frailty have a highmortality risk following hip fracture. The CFS is an excellent prognostic tool for mortality following hip fracture for patients living with CKD and could be easily incorporated into routine clinical practice. Further studies are required to evaluate interventions that aim to improve outcomes following hip fracture for patients with CKD, particularly those with CKD and living with frailty.

\section{Appendix}

Appendix is adapted from the supplementary table 4 in Nixon AC, Bampouras TM, Pendleton et al. (2019) Diagnostic Accuracy of Frailty Screening Methods in Advanced Chronic Kidney Disease. Nephron 141: 147-155, requiring permission from S. Karger AG for re-use. (Table 3)

Acknowledgements The authors would like to acknowledge the (nonfinancial) support received from the Lancashire Clinical Research Facility, National Institute of Health Research, U.K. for this submitted work.

Author contributions Conceptualization: HHLW, SM, APD, ACN; Methodology: HHLW, ACN; Formal Analysis and Investigation: HHLW, RV-M, GMcL, KC, ACN; Writing - original draft preparation: HHLW, ACN; Writing-review and editing: HHLW, RV-M, GMcL, KC, SM, APD, ACN; Funding acquisition—not applicable; Resources: HHLW, RV-M, ACN; Supervision: ACN.

Funding There was no external funding for this article.

\section{Compliance with ethical standards}

Conflicts of interest H.H.L. Wu, R. Van-Mierlo, G. McLauchlan, K. Challen, S. Mitra and A.P. Dhaygude declared no competing interests for this submitted work. A.C. Nixon reports a grant from Kidney Research UK outside of this submitted work.

Availability of data and material The authors agree that the data and material published in this article could be available transparently.

Open Access This article is licensed under a Creative Commons Attribution 4.0 International License, which permits use, sharing, adaptation, distribution and reproduction in any medium or format, as long as you give appropriate credit to the original author(s) and the source, provide a link to the Creative Commons licence, and indicate if changes were made. The images or other third party material in this article are included in the article's Creative Commons licence, unless indicated otherwise in a credit line to the material. If material is not included in the article's Creative Commons licence and your intended use is not permitted by statutory regulation or exceeds the permitted use, you will need to obtain permission directly from the copyright holder. To view a copy of this licence, visit http://creativecommons.org/licenses/by/4.0/.

\section{References}

1. Papadimitriou N, Tsilidis KK, Orfanos P et al (2017) Burden of hip fracture using disability-adjusted life-years: a pooled analysis of prospective cohorts in the CHANCES consortium. Lancet Publ Health 2:e239-e246

2. Cooper C, Cole ZA, Holroyd CR et al (2011) Secular trends in the incidence of hip and other osteoporotic fractures. Osteoporos Int 22:1277 
3. Naylor KL, McArthur E, Leslie WD et al (2014) The threeyear incidence of fracture in chronic kidney disease. Kidney Int 86:810-818

4. Mittalhenkle A, Gillen DL, Stehman-Breen CO (2004) Increased risk of mortality associated with hip fracture in the dialysis population. Am J Kidney Dis 44:672-679

5. Nickolas TL, McMahon DJ, Shane E (2006) Relationship between moderate to severe kidney disease and hip fracture in the United States. J Am SocNephrol 17:3223-3232

6. Zhang Q, Ma Y, Lin F et al (2020) Frailty and mortality among patients with chronic kidney disease and end-stage renal disease: a systematic review and meta-analysis. Int UrolNephrol $52: 363-370$

7. Moorthi RN, Avin KG (2017) Clinical relevance of sarcopenia in chronic kidney disease. Current Op NephrolHypertens 26:219-228

8. Martin KJ, González EA (2007) Metabolic bone disease in chronic kidney disease. J Am SocNephrol 18:875-885

9. Ouellet JA, Ouellet GM, Romegialli AM et al (2019) Functional outcomes after hip fracture in independent community-dwelling patients. J Am GeriatrSoc 67:1386-1392

10. Bentler SE, Liu L, Obrizan M et al (2009) The aftermath of hip fracture: discharge placement, functional status change, and mortality. Am J Epidemiol 170:1290-1299

11. Marufu TC, White SM, Griffiths R et al (2016) Prediction of 30 day mortality after hip fracture surgery by the nottingham hip fracture score and the surgical outcome risk tool. Anaesthesia $71: 515-521$

12. Marufu TC, Mannings A, Moppett IK (2015) Risk scoring models for predicting peri-operative morbidity and mortality in people with fragility hip fractures: qualitative systematic review. Injury 46:2325-2334

13. Tsang C, Boulton C, Burgon V et al (2017) Predicting 30 day mortality after hip fracture surgery: evaluation of the National Hip Fracture Database case-mix adjustment model. Bone Joint Res 6:550-556

14. Rockwood K, Song X, MacKnight C et al (2005) A global clinical measure of fitness and frailty in elderly people. CMAJ 173:489-495

15. Hewitt J, Carter B, Vilches-Moraga A et al (2020) The effect of frailty on survival in patients with COVID-19 (COPE): a multicentre, European, observational cohort study. Lancet Publ Health 5:e444-e451

16. Nixon AC, Bampouras TM, Pendleton N et al (2019) Diagnostic accuracy of frailty screening methods in advanced chronic kidney disease. Nephron 141:147-155

17. Rockwood K, McMillan M, Mitnitski A et al (2015) A frailty index based on common laboratory tests in comparison with a clinical frailty index for older adults in long-term care facilities. J Am Med DirAssoc 16:842-847

18. Blodgett JM, Theou O, Howlett SE et al (2016) A frailty index based on laboratory deficits in community-dwelling men predicted their risk of adverse health outcomes. Age Ageing 45:463-468

19. Charlson M, Szatrowski TP, Peterson J et al (1994) Validation of a combined comorbidity index. J ClinEpidemiol 47:1245-1251

20. Buntinx F, Niclaes L, Suetens C et al (2002) Evaluation of Charlson's comorbidity index in elderly living in nursing homes. J ClinEpidemiol 55:1144-1147

21. Dripps RD (1963) New classification of physical status. Anesthesiology 24:111

22. Maxwell MJ, Moran CG, Moppett IK (2008) Development and validation of a preoperative scoring system to predict 30 day mortality in patients undergoing hip fracture surgery. $\mathrm{Br} \mathbf{J}$ Anaesth 101:511-517
23. Rogmark C, Carlsson A, Johnell O et al (2002) A prospective randomised trial of internal fixation versus arthroplasty for displaced fractures of the neck of the femur. Functional outcome for 450 patients at two years. J Bone Joint Surg Br 84:183-188

24. Karnofsky DA, Burchenal JH (1949) The clinical evaluation of chemotherapeutic agents in cancer. In: MacLeod CM (ed) Evaluation of chemotherapeutic agents. Columbia University Press, New York, pp 196-196

25. Hlatky MA, Boineau RE, Higginbotham MB et al (1989) A brief self-administered questionnaire to determine functional capacity (The Duke Activity Status Index). Am J Cardiol 64:651-654

26. Cureton KJ, Sloniger MA, O'Bannon JP et al (1995) A generalized equation for prediction of $\mathrm{VO}_{2}$ peak from 1 mile run/walk performance. Med Sci Sports Exerc 27:445-451

27. Green $\mathrm{S}$, Askew $\mathrm{C}$ (2018) $\mathrm{VO}_{2}$ peak is an acceptable estimate of cardiorespiratory fitness but not $\mathrm{VO}_{2}$ max. J ApplPhysiol 125:229-232

28. Nitsch D, Mylne A, Roderick PJ et al (2008) Chronic kidney disease and hip fracture-related mortality in older people in the UK. Nephrol Dial Transplant 24:1539-1544

29. Kim SM, Long J, Montez-Rath M et al (2016) Hip fracture in patients with non-dialysis-requiring chronic kidney disease. $\mathrm{J}$ Bone Miner Res 31:1803-1809

30. Black DM, Rosen CJ (2016) Postmenopausal osteoporosis. New Engl J Med 374:254-262

31. Hickson LJ, Farah WH, Johnson RL et al (2018) Death and postoperative complications after hip fracture repair: dialysis effect. Kidney Int Rep 3:1294-1303

32. Delgado C, Shieh S, Grimes B et al (2015) Association of selfreported frailty with falls and fractures among patients new to dialysis. Am J Nephrol 42:134-140

33. Ponnusamy KE, Jain A, Thakkar SC et al (2015) Inpatient mortality and morbidity for dialysis-dependent patients undergoing primary total hip or knee arthroplasty. J Bone Joint Surg 97:1326-1332

34. Keating JF, Grant A, Masson M et al (2006) Randomized comparison of reduction and fixation, bipolar hemiarthroplasty, and total hip arthroplasty: treatment of displaced intracapsular hip fractures in healthy older patients. J Bone Joint Surg 88:249-260

35. McRae R (1994) Practical fracture treatment. Churchill Livingstone, Edinburgh

36. Rogmark C, Johnell O (2006) Primary arthroplasty is better than internal fixation of displaced femoral neck fractures: a meta-analysis of 14 randomized studies with 2289 patients. Acta Orthop 77:359-367

37. Stehman-Breen CO, Sherrard DJ, Alem AM et al (2000) Risk factors for hip fracture among patients with end-stage renal disease. Kidney Int 58:2200-2205

38. Saad A, Shahban S, Sonsale P et al (2018) Do pre-operative blood tests predict patient length of stay in elective total hip replacement? ClinPract 15:853-859

39. Ding BT, Shinde A, Tan KG (2019) Hip hemiarthroplasty for femoral neck fractures in end-stage renal disease patients on dialysis compared to patients with late-stage chronic kidney disease. Singapore Med J 60:403-408

40. Bruyère $\mathrm{O}$, Buckinx $\mathrm{F}$, Beaudart $\mathrm{C}$ et al (2017) How clinical practitioners assess frailty in their daily practice: an international survey. Aging ClinExp Res 29:905-912

41. NICE guideline (2020) COVID-19 rapid guideline: critical care in adults. NICE https://www.nice.org.uk/guidance/ng159. Accessed 15 March 2020

42. Neuhaus V, King J, Hageman MG et al (2013) Charlson comorbidity indices and in-hospital deaths in patients with hip fractures. ClinOrthopRelat Res 471:1712-1719 
43. Kirkland LL, Kashiwagi DT, Burton MC et al (2011) The Charlson comorbidity index score as a predictor of 30 day mortality after hip fracture surgery. Am J Med Qual 26:461-467

44. Tarride JE, Burke N, Leslie WD et al (2016) Loss of health related quality of life following low-trauma fractures in the elderly. BMC Geriatr 16:84

45. Johnson DJ, Greenberg SE, Sathiyakumar V et al (2015) Relationship between the Charlson comorbidity index and cost of treating hip fractures: implications for bundled payment. J OrthopTraumatol 16:209-213

46. Aigner R, Meier Fedeler T, Eschbach D et al (2016) Patient factors associated with increased acute care costs of hip fractures: a detailed analysis of 402 patients. Arch Osteoporos 11:38

47. Ritchie JP, Alderson H, Green D et al (2014) Functional status and mortality in chronic kidney disease: results from a prospective observational study. Nephron 128:22-28

48. Jassal SV, Karaboyas A, Comment LA et al (2016) Functional dependence and mortality in the international dialysis outcomes and practice patterns study (DOPPS). Am J Kidney Dis 67:283-292
49. Sakabe T, Imai R, Murata H et al (2006) Life expectancy and functional prognosis after femoral neck fractures in hemodialysis patients. J Orthop Trauma 20:330-336

50. Buecking B, Eschbach D, Knobe M et al (2017) Predictors of noninstitutionalized survival 1 year after hip fracture: a prospective observational study to develop the Marburg Rehabilitation Tool for Hip fractures (MaRTHi). Medicine 96:e7820

51. Wiles MD, Moran CG, Sahota O et al (2011) Nottingham Hip Fracture Score as a predictor of one year mortality in patients undergoing surgical repair of fractured neck of femur. Br J Anaesth 106:501-504

52. Dawe EJ, Lindisfarne E, Singh T et al (2013) Sernbo score predicts survival after intracapsular hip fracture in the elderly. Ann R Coll SurgEngl 95:29-33

Publisher's Note Springer Nature remains neutral with regard to jurisdictional claims in published maps and institutional affiliations. 